\title{
Clinical study of primary caesarean section in multiparous women in a tertiary care hospital
}

\author{
Rupal Samal*, Pallavee Palai, Seetesh Ghose
}

Department of Obstetrics and Gynaecology, Mahatma Gandhi Medical College, SBV University, Pondicherry, India

Received: 28 February 2016

Revised: 13 March 2016

Accepted: 14 April 2016

\section{*Correspondence:}

Dr. Rupal Samal,

E-mail: rupalsamal1@gmail.com

Copyright: (c) the author(s), publisher and licensee Medip Academy. This is an open-access article distributed under the terms of the Creative Commons Attribution Non-Commercial License, which permits unrestricted non-commercial use, distribution, and reproduction in any medium, provided the original work is properly cited.

\begin{abstract}
Background: The objective of this study was to find the incidence and indications of primary caesarean section in parous women and evaluate the maternal and perinatal outcomes there from.

Methods: Prospective study of primary caesarean sections in parous women at our institute from June 2013 to May 2014 was done. Age, indications and the maternal as well as perinatal outcomes were analyzed. Data was expressed as number and percentage.

Results: Out of 1124 caesarean deliveries, 68 primary caesareans in parous women were done. The most common age group was 21-30 years. The majority of parous women who underwent primary caesarean section, were para 2. Booked cases constituted the maximum number of such women at $97.1 \%(n=66)$. In parous women undergoing primary caesarean section, the number of spontaneous onset of labour was significantly more than those undergoing induction of labour. The most common indication for caesarean section in this group of patients was fetal distress. There was no neonatal mortality or adverse maternal outcome.

Conclusions: Fetal distress was the most common indication for primary caesarean section in the parous woman, although malpresentation also contributed significant numbers. Primary caesarean sections in women with previous vaginal deliveries, were not associated with any significant neonatal or maternal complications.
\end{abstract}

Keywords: Primary caesarean section, Multipara, Foetal distress

\section{INTRODUCTION}

Primary caesarean deliveries are an important target for reduction in numbers, because they lead to an increased risk for a repeat caesarean delivery. ${ }^{1}$ Delivery by caesarean section is most frequently performed in nulliparous for dystocia with suspected cephalopelvic disproportion. At the same time the abnormalities most common in multipara such as transverse lie, placenta praevia are encountered less often than in former. ${ }^{2}$ One of the primary causes of rising trend in the rates of cesarean sections is the increase in number of such deliveries in primigravida. However, an upward trend of primary caesareans among parous women has also contributed to the elevated rates.
Primary caesarean section in multipara means the first caesarean section done in patients who had vaginal delivery once or more before. The present study evaluates the proportion of primary caesarean sections occurring in multipara in a tertiary care hospital and their indications. This study also assesses the maternal and perinatal outcomes of these women.

\section{METHODS}

An observational study was conducted in the Obstetrics unit of Mahatma Gandhi Medical College and Research Institute, Pondicherry for a period of one year from June 2013 to June 2014. All multiparous women (gestational age $>28$ weeks) with a singleton pregnancy and previous normal delivery who underwent caesarean section were 
included in the study. Women with scarred uterus or anomalous fetus diagnosed antenatally or during delivery were excluded from the study. History of the patient was reviewed. Intraoperative details were noted and patients were followed up till discharge from the hospital. Data collected and analysed were: demographic details like age, parity, booking status; antenatal high risk factors; indication of the caesarean section; timing of caesarean section; intra-operative and postpartum complications; Apgar score of the baby; neonatal intensive care unit (NICU) admission; birth weight and neonatal morbidity/mortality. The obtained data was statistically processed using MS Excel program. Analysis was done with simple descriptive statistics and presented as frequency tables.

\section{RESULTS}

Table 1: Proportion of caesarean sections in multipara.

\begin{tabular}{|lll|}
\hline Incidence & No of cases & $\%$ \\
\hline Total no of caesarean section & 1124 & 100 \\
\hline $\begin{array}{l}\text { No. of primary caesarean section } \\
\text { in parous women }\end{array}$ & 68 & 6.04 \\
\hline
\end{tabular}

During the study period 1124 caesarean deliveries were conducted in our hospital. Table 1 show that the proportion of caesarean sections in parous women was $6.04 \%$. This study included these 68 cases of primary caesarean section in multigravida.

Table 2: Age distribution of the cases.

\begin{tabular}{|lll|}
\hline Age (yrs) & No. of patients & $\%$ \\
\hline $21-30$ & 57 & 83.8 \\
\hline $31-40$ & 11 & 16.2 \\
\hline Total & 68 & 100 \\
\hline
\end{tabular}

Mean \pm SD: $27.43 \pm 3.76$ yrs

Table 2 shows that the mean age of parous women undergoing primary caesarean was 27 years. The maximum incidence of caesarean section was seen in the age group of 21-30 yrs.

Table 3: Parity distribution of cases.

\begin{tabular}{|lll|}
\hline Parity & No of patients & $\%$ \\
\hline 2nd & 38 & 55.88 \\
\hline 3rd & 20 & 29.41 \\
\hline 4th & 8 & 11.74 \\
\hline 5 th & 2 & 2.95 \\
\hline Total & 68 & 100.0 \\
\hline
\end{tabular}

Parity varied from 2 to 5 and the majority of the patients were $2^{\text {nd }}$ gravida (Table 3 ).

Majority of these women were booked cases (Table 4). Only $2.9 \%$ patients did not receive any antenatal care. $50 \%$ patients $(n=34)$ had some risk factors complicating pregnancy. Figure 1 shows the break-up of these antenatal risk factors. $76.5 \%$ patients had spontaneous onset of labour, while others underwent induction (Table 5).

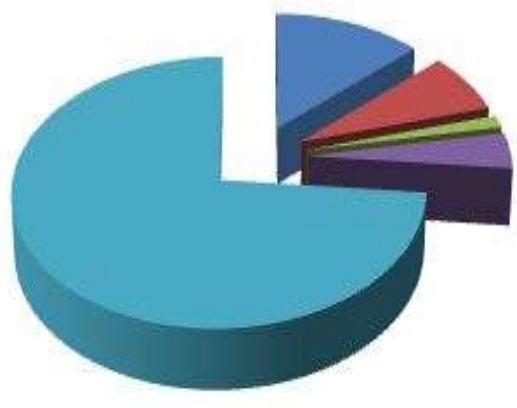

GDM on diet control - Gest HTN

Overt DM

on insulin

Severe

anemia

Others

Table 4: Booking status of cases.

\begin{tabular}{|lll|}
\hline Booking status & No of patients & $\%$ \\
\hline Booked & 66 & 97.1 \\
\hline Unbooked & 2 & 2.9 \\
\hline Total & 68 & 100.0 \\
\hline
\end{tabular}

Table 5: Type of labour.

\begin{tabular}{|lll|}
\hline Type of labour & No of patients & $\%$ \\
\hline Induced & 16 & 23.5 \\
\hline Spontaneous & 52 & 76.5 \\
\hline Total & 68 & 100.0 \\
\hline
\end{tabular}

The three most common indications for caesarean sections as represented in (Table 6) were fetal distress (42.6\%), malpresentation $(26.4 \%)$ and cephalopelvic disproportion (CPD, 14.7\%).

Table 6: Indication for caesarean section.

\begin{tabular}{|lll|}
\hline Indications & No of patients & $\%$ \\
\hline Fetal distress & 29 & 42.6 \\
\hline Malpresentation & 18 & 26.4 \\
\hline CPD & 10 & 14.7 \\
\hline Placenta praevia & 4 & 5.9 \\
\hline Failed induction & 3 & 4.5 \\
\hline IUGR with severe oligo & 2 & 2.9 \\
\hline Cord prolapse & 1 & 1.5 \\
\hline Non-reassuring FHR & 1 & 1.5 \\
\hline Total & 68 & 100.0 \\
\hline
\end{tabular}

Malpresentation was present in $26.4 \%$ of the cases (Table 7). $22.1 \%$ babies were admitted to NICU. Only $5.1 \%$ babies had Apgar $<7$ at $1 \mathrm{~min}$. 26.5\% neonates had low birth weight (LBW). There was no neonatal mortality. No adverse maternal outcomes observed in the study. 
Table 7: Incidence of various obstetric presentations.

\begin{tabular}{|lll|}
\hline Presentation & No. of patients & $\%$ \\
\hline Breech & 11 & 6.2 \\
\hline Brow & 2 & 2.9 \\
\hline Cephalic & 50 & 73.5 \\
\hline Face & 1 & 1.5 \\
\hline Footling & 1 & 1.5 \\
\hline Transverse & 3 & 4.4 \\
\hline Total & 68 & 100.0 \\
\hline
\end{tabular}

\section{DISCUSSION}

\section{Incidence of primary caesarean sections in multipara}

Multiparity is often associated with poverty, illiteracy, ignorance and lack of knowledge of the available antenatal care and family planning methods. A multipara who has earlier delivered vaginally, may still require a caesarean section for safe delivery. ${ }^{2}$ Caesarean section is not the panacea for all obstetric problems, but it is an excellent solution when applied judiciously. Incidence of primary caesarean sections in multipara in the present study is $6.04 \%$. Compared to other studies conducted by Desai et al, whose incidence was $29.05 \%$ and Hemabindu et al whose incidence was on higher side that is $40 \%$, our incidence was appreciably lower. ${ }^{2,3}$ The higher incidence in the other studies might have been due to negligence on the part of the patients towards antenatal care, which is reflected in the fact that most of the patients in that study were unbooked and hospitals were referral tertiary centre for high risk cases. In the present study the maximum number of women undergoing primary caesarean section amongst multigravida was in the age group of 21-30 years, which is comparable to Eastman et al study where majority of the patients (40\%) belonged to 25-29 years of age. ${ }^{4}$ This may be due to the trends of early marriage and lack of education resulting in high fertility in early ages. In the Parrish series, the maximum number of patients was in the age group of $>40$ years. ${ }^{5}$ This may be due to older childbearing women and delay in childbirth in the USA.

Nearly $55.88 \%, 29.41 \%, 11.74 \%$ and $2.94 \%$ patients were in the second, third, fourth and fifth gravida respectively which is comparable with the study conducted by Desai et al. ${ }^{2}$ The percentages of booked and unbooked cases in our present study are $97.1 \%$ and $2.9 \%$ respectively.

In comparison, Desai et al had $27.90 \%, 72.09 \%$ of booked and unbooked cases respectively and in Hemabindu et al study $71 \%$ were unbooked. ${ }^{2,3}$ In the present study elective caesarean sections account for only $5.9 \%$ cases and emergency caesareans were $94.1 \%$ which is comparable to the study done by Desai et al where they had only $3 \%$ elective caesarean sections. ${ }^{2}$

\section{Indications for primary caesarean sections in the multipara}

There were different indications for caesarean sections in these patients. Fetal distress was the commonest indication having the higher number of cases $29(42.6 \%)$, followed by malpresentation (26.4\%) and CPD (14.7\%). In malpresentation, breech $(73.5 \%)$ was the most common. Similarly in the study by Desai et al, fetal distress $(25.58 \%)$, antepartum haemorrhage (APH, $22.09 \%)$, CPD (19.77\%) and abnormal presentations (17.44\%) were the most common indications for caesarean sections. ${ }^{2}$ Both the studies were therefore comparable. Fetal distress is a common indication for lower segment caesarean section in multipara. The incidence of fetal distress in the present study is slightly more as compared to other studies. This can be attributed to frequent use of fetal monitoring (cardiotocogram) as an integral part of labour and delivery care in recent years as compared to previous decades.Fetal heart rate changes in CTG indicate fetal distress which prompts the obstetrician to perform rapid delivery by CS. And also universal use of fetal scalp blood sampling is unavailable thereby leading to obstetrician's distress. However, no obstetrician would like to take the risk of not performing CS. ${ }^{4,5}$ Malpresentations are more common in a grand multipara and are favoured by a pendulous abdomen and lordosis of the lumbar spine. Transverse lie is the most common malpresentation encountered. According to Eastman et al, the causes of transverse lie are: a) abnormal relaxation of the abdominal wall b) pelvic contraction and c) placenta praevia. ${ }^{4}$ Klein states that multipara in early labour with fetal head not engaged should receive the same careful investigation for cephalopelvic disproportion that a primigravida would receive. ${ }^{6}$ The fact that the multipara has had one or more vaginal deliveries should be regarded as an optimistic fact but not diagnostic criteria for spontaneous delivery of the fetus. Reluctance to diagnose this cephalopelvic disproportion leads to a longer labour, with development of excessive moulding and caput formation which makes the observer to believe that progress has been made. ${ }^{5}$ Many times, delivery with forceps is attempted and fails. Duckman et al state that cephalopelvic disproportion in a multipara can be more significant and more dangerous than in the primi because of the delay in recognition. ${ }^{7}$ Earliest recognition of its existence is made possible by more frequent discussion of the problem. Hence the philosophy towards CPD should be re-evaluated with a more liberal and earlier use of caesarean section. Caesarean section rates may increase slightly but healthier infants and mothers will more than offset the slight change in statistics.

\section{Maternal and perinatal outcomes of primary caesarean sections in the multipara}

In the present study, there was no maternal mortality. This may be because of availability of antibiotics, blood transfusion facilities, and safe methods of anaesthesia, 
timely intervention, better surgical techniques and operative skill of the obstetricians. It could also be due to good obstetric intensive care unit facilities for critically obstetric patients. In our study, $22.1 \%$ babies were admitted to NICU. Only 5.1\% babies had Apgar score <7 at $1 \mathrm{~min}$. $26.5 \%$ neonates had LBW. There was no neonatal mortality. Hence a multipara woman in labor requires the same attention as that of primigravida. Good antenatal and intrapartum care and early referral can reduce the maternal and perinatal morbidity and mortality in multipara. An older study in an almost identical patient population, conducted on grand multipara a few decades back reported maternal mortality of $2.67 \% .^{7}$ The perinatal mortality in the same study was significantly higher in grand multiparas delivered by primary caesarean section (17.2\%), compared to only $6.7 \%$ in primigravidas delivered abdominally. ${ }^{8,9}$ The authors explained this difference by the fact that primary caesarean sections were performed in a large number of grand multiparas for maternal rather than fetal indications. The fetal loss in all grand multiparas was as a result of the fetal risks inherent in the indications for caesarean section. This, in essence reflects the change in management over the last few decades in the multipara. The commonest indication in our population was fetal distress, and not a maternal indication. Obstetricians in current practice have a lower threshold to opt for an abdominal delivery to salvage the fetus at an earlier time point than previously. ${ }^{10}$ Without doubt improvement in safety of caesarean sections as well as better intensive care backup for both the mother and the neonate has influenced such practice. The change has also probably been ushered in by increasing acceptance of the fact that every multiparous lady cannot be expected to deliver normally. Thus, multipara in labour are supervised with utmost vigilance since a wide variety of unforeseen complications may occur in them.

\section{CONCLUSION}

Multiparity with previous vaginal delivery is regarded as an optimistic historical fact, not a diagnostic criteria for spontaneous delivery in next pregnancy. Good obstetric practice involving antenatal and intrapartum care can reduce the rate of caesarean sections in the multigravida. However, previous vaginal delivery gives a false sense of security to the patient as well as to the relatives. Caesarean section becomes mandatory in some situations. Hence a multiparous woman in labour requires the same attention as required by a primigravida.

\section{Funding: Not required}

Conflict of interest: None declared

Ethical approval: The study was approved by the Institutional Ethics Committee

\section{REFERENCES}

1. Susan F, Claudia A, Zhang J, Lawrence W. A national estimate of elective caesarean delivery rate. J Obstet Gynecol. 2005;105(9):751-6.

2. Desai E, Leuva H, Leuva B, Kanani M. A study of primary caesarean section in multipara. Int J Reprod Contracept Obstet Gynecol. 2013;5(2):320-4.

3. Himabindu P, Tripura SM, Sireesha KV, Sairam MV. Primary Caesarian Section in Multipara. IOSRJDMS. 2015;14(5):22-5.

4. Eastman N. Multiparity and its effect on maternal and perinatal mortality. Obstet Gynecol Surv. 1988;13(5):833-7.

5. Parrish KM, Holt VL, Earterling TR, Connell FA, Logerfero JP. Effect of changes in maternal age, parity and birth weight distribution on primary caesarean delivery rates. Journal of American Medical Association. 1994;271(3):443-7.

6. Klein D, Rymonds R, Gabaeff L. Primary cesarean section in multipara. Am J Obstet Gynecol. 1963;87(4):242-52.

7. Duckman S, Chen W, Gungor T, Bonura F. Disproportion in multipara, fact or philosophy. Am J Obstet Gynecol. 1998;101(7):1001-15.

8. Palanichamy G. A study of 900 primary caesarean sections with special reference to 151 primary caesarean sections in grand multipara. J Obstet \& Gynec India. 2000;26(6):374-9.

9. Purandare CN. The Over Roofing Rates of Caesarean Section. The Journal of Obstetrics and Gynecology of India. 2011;61(5):501-2.

10. Sethi P, Vijaylaxmi S, Shailaja G, Trupti B, Devi S. A study of primary cesarean section in multigravida. Perspectives in medical research. 2014;2:3-7.

Cite this article as: Samal R, Palai $\mathrm{P}$, Ghose $\mathrm{S}$. Clinical study of primary caesarean section in multiparous women in a tertiary care hospital. Int $\mathbf{J}$ Reprod Contracept Obstet Gynecol 2016;5:1506-9. 